\title{
Descentralização e participação social: o novo desenho das políticas sociais
}

\author{
Solange Maria Teixeira
}

Universidade Federal do Piauí (UFPI)

\section{Descentralização e participação social: o novo desenho das políticas sociais}

Resumo: Este texto aponta elementos para uma problematização da democracia direta, materializada em processos de descentralização e de participação da sociedade civil nos espaços de deliberações das políticas públicas, em um contexto de reformas das políticas sociais, iniciadas na década de 1990. Toma como objeto de análise a Política Nacional do Idoso e as experiências dos conselhos de direito da pessoa idosa. Conclui-se que, apesar dos espaços de participação serem contraditórios e os sentidos de participação dos diferentes sujeitos estarem em confronto, a correlação de forças, favorável às forças conservadoras, redireciona as políticas sociais, imprimindo-lhes nova racionalidade e nova legitimidade, que distribuem responsabilidades para a sociedade civil. Essas mudanças reforçam a cultura privacionista no enfrentamento das refrações da questão social e transmutam a participação popular em consentimento e legitimação da ordem.

Palavras-chave: democracia direta, participação social, descentralização, Política Nacional do Idoso.

\section{Decentralization and Social Participation: the New Design of Social Policies}

Abstract: This text indicates essential elements needed for an analysis of direct democracy, materialized in processes of decentralization and civil society participation in spaces for deliberating public policies, in a context of reform of these policies in the 1990's. It analyzes the national Policy for the Elderly and the experiences of elderly rights councils. It concludes that despite the fact that spaces for participation are contradictory and the orientations of participation of the various subjects are in conflict, the correlation of forces favorable to conservative forces, redirect social policies, giving them a new rationality and new legitimacy that distribute responsibilities to civil society. These changes reinforce a culture of privation in light of the clashes of the refractions of the social issue and transmute popular participation into consent and legitimization of the given order.

Key words: direct democracy, social participation, decentralization, National Policy for the Elderly. 


\section{Introdução}

A Constituição Federal de 1988 (BRASIL, 1999) instaura elementos democráticos na gestão das políticas públicas, que sugerem um novo desenho das políticas sociais no Brasil, fundamentados nos princípios da descentralização, municipalização e participação da sociedade civil em todo o processo. Estabelece que as políticas sociais sejam desenvolvidas de modo democrático, em que a sociedade, via órgãos representativos, participe dos espaços de deliberações das diretrizes das políticas, do planejamento, da execução, do controle e da supervisão dos planos, programas e projetos.

Como destaca Paulo Netto (1999, p. 77), a Constituição de 1988 impôs, ainda que tardiamente, o "pacto de classes", garantindo direitos e proteção social pública aos trabalhadores, que, mesmo "sem ferir a ordem burguesa [...], ela assentou os fundamentos a partir dos quais a dinâmica capitalista poderia ser direcionada de modo a reduzir, a níveis toleráveis, o que os próprios segmentos das classes dominantes então denominavam "dívida social'". O desenho das políticas sociais apontava, então, em direção à modificação do modelo de proteção social brasileiro, tais como: as tendências à universalização, ao redistributivismo, à inovação na estrutura administrativa - como a descentralização política, a participação social - e a responsabilização pública, via fundos públicos, pela proteção social.

A trajetória dos anos 1990, todavia, não seguiu o ideário da Constituição, instaurando uma conjuntura de reformas, antes mesmo da implementação dos princípios constitucionais - uma reestruturação conservadora que inviabilizou suas tendências progressistas. Como destaca Vianna (2002), apesar de manter o conceito de seguridade social, medidas são tomadas que inviabilizam a clareza de suas proposições e sua efetivação prática. Num contexto em que o endurecimento das pressões dos credores externos, a disputa por recursos escassos, a desmobilização da sociedade e uma série de outros fatores enfraqueceram a coalização de apoio àquele ideário, modificações foram feitas separando as áreas e políticas da seguridade, além de modificações na administração, no financiamento, e inúmeras reformas na previdência social.

Essas reformas são condizentes com as medidas de ajuste estrutural, impostas pelos mecanismos financeiros internacionais que desencadearam mudanças mediante políticas liberalizantes, privatizantes e de mercado, condição de inserção do país na nova ordem mundial globalizada, atingindo as políticas públicas de corte social, através das noções de redução de déficits públicos e de reforma do Estado.

São reformas representativas de uma nova forma de enfrentamento da questão social pelo capital e
Estado, que têm reforçado a cultura privacionista no trato de suas refrações, expressa na assunção das responsabilidades para a sociedade civil ou na coresponsabilidade (não apenas do setor mercantil, mas também do não-mercantil), de modo a diminuir a demanda social do Estado. É uma forma de transmutar problemas sociais em assunto privado, de responsabilidade da família, comunidade, organizações nãogovernamentais, redirecionando a participação popular sugerida pela Constituição ao processo de implementação das políticas, inclusive com trabalho voluntário, recursos e infra-estrutura da sociedade civil, ou seja, em cooperativismo, em solidariedade entre sujeitos antagônicos.

Essas 'novas' formas de trato da questão social fazem parte das estratégias de redução do Estado como gestor e administrador da proteção social aos trabalhadores, do desmonte dos direitos sociais conquistados, sob a retórica de ampliação da participação da sociedade civil, da solidariedade indiferenciada, do cooperativismo de todos perante as crises e a agudização da questão social, bases da recomposição da hegemonia das classes dominantes nas novas relações de produção e reprodução social.

A referida hegemonia da classe dominante ou a recomposição de suas bases nasce na produção, na empresa capitalista, como condição ideológica necessária à reestruturação dos processos produtivos das relações de trabalho, mediante mecanismos de captura da subjetividade materializada nas estratégias de participação e cooperativismos do trabalhador. No âmbito da reprodução social (dimensão político-ideológica da reestruturação), atinge o modo de fazer política e se consubstancia nas estratégias de 'participação solidária' da sociedade civil, que tem reatualizado estratégias históricas de respostas às mazelas sociais, como a filantropia, o trabalho voluntário, o cooperativismo, dentre outras. Essa 'participação solidária' das organizações da sociedade civil, que se auto-intitulam públicas, porém não-estatais, parte da 'esfera pública', é resultante das novas simbioses entre 'público' e 'privado', da penetração do 'privado' no espaço 'público', e do referido cooperativismo entre sujeitos antagônicos frente às questões sociais.

Assim, institui-se um 'novo' modo de fazer política social "pelo qual se imputa a lógica do público nãoestatal na cultura e nas práticas organizacionais, e esvazia-se o caráter público, e como tal, universal, na prestação de serviços sociais e execução de políticas sociais" (GUERRA, 2005, p. 8); redireciona a noção de participação social dos movimentos democráticos da década de 1980, por descentralização política, por participação nos processos decisórios da política, por mecanismos de controle social, transformando-os em espaços de consentimento, de legitimação de decisões dos governos, de responsabilização pela proteção. 
O objetivo deste artigo é demonstrar como esse modelo de fazer política social, que se diz democrático, de gestão participativa, consolida uma direção que não rompe com os princípios postos pela Constituição, mas a redireciona. Consolidando, legalizando e legitimando o mix público/privado e a noção de participação como divisão de responsabilidades pela proteção social, assumida, inclusive, pelos movimentos sociais, gerando um senso comum, um consenso em torno desse modelo. Destacaremos como objeto de análise a política social de proteção ao idoso, mas poderia ser a de assistência à criança e ao adolescente, ou outra qualquer que tenha sido criada a partir da década de 1990.

\section{Institucionalização de uma 'nova' cultura de fazer política social}

No contexto da análise das transformações dos sistemas de proteção social, sob os efeitos de restrições econômico-financeiras pós-anos 1970, a sociedade civil aparece com renovado papel no que se refere às questões sociais.

Os determinantes desses processos imediatos são as transformações no sistema produtivo. Essas não revelam apenas uma modificação técnica e tecnológica dos processos de trabalho, mas também uma ofensiva classista que visa antes atingir a classe trabalhadora, tanto em seus mecanismos de organização, quanto em suas conquistas históricas de proteção pública, deslegitimando o espaço público (estatal), e instaurando um 'novo' tratamento dos problemas sociais no campo moral, solidário e voluntário da ajuda da sociedade civil.

Nessa perspectiva, a ofensiva do capital, como resposta à crise na década de 1970, expressa-se pelo processo de reestruturação produtiva impulsionado pela terceira revolução industrial, que incorpora avanços tecnológicos, reduzindo cada vez mais o trabalho vivo e ampliando, sem precedentes, o desemprego, cujas dimensões estruturais engendram formas de precariedades nas suas condições. Expressa-se, também, por uma ofensiva político-ideológica, de recomposição das bases de hegemonia do capital consubstanciada na busca da captura da subjetividade do trabalhador, mediante a cooperação no processo produtivo e fora dele, difundindo uma cultura solidarista entre classes antagônicas; deslegitimando a solidariedade social ${ }^{1}$ administrada pelo Estado que deu origem as políticas públicas de corte social; reatualizando práticas filantrópicas e o trabalho voluntário; e viabilizando a mercantilização de serviços sociais para o público que pode pagar por eles.

Essa cultura solidarista, como destaca Abreu et al (2002), dissimula as consequiências das saídas neoliberais do capital a essa nova crise cíclica, dado que aprofundam as desigualdades sociais e acirram os antagonismos entre classes sociais - condição e grande ameaça desse padrão de acumulação. Nesse processo, a solidariedade entre sujeitos antagônicos, isto é, entre capital e trabalho, reafirma-se como uma estratégia ideológica de controle social face ao agravamento e ao enfrentamento da questão social, base da constituição dos processos político-pedagógicos na organização da cultura dominante - como cultura que se prende ao consenso.

O capital tem, historicamente, mobilizado mecanismos de contratendência para enfrentar as crises cíclicas de sua reprodução, imprimindo redefinições nas suas práticas e na intervenção do Estado, esta também determinada pelas lutas de classes. Todavia, o fracasso completo da experiência do chamado socialismo real nos países do Leste Europeu e a pulverização das lutas das classes subalternas em torno de direitos por categoriais específicas - produto da democracia burguesa - deram origem a uma correlação de forças, em que as forças conservadoras ganharam terreno na orientação econômica, política e social, apesar das resistências da classe trabalhadora - atingida pela redução do proletariado, pela formação do subproletariado, pelos desempregados e pelo surgimento de um neocorporativismo nos seus movimentos de classe.

É nesse cenário que as forças conservadoras tentam redirecionar as mudanças na regulação estatal à luz das idéias neoliberais e ganham repercussões internacionais, fortalecidas pelas tendências da reestruturação do capital e pela ausência de contraponto ou ofensivas unificadas contrárias. O Estado intervencionista (na reprodução do capital e trabalho) passa a ser o alvo das críticas. E responsabilizado pelas crises econômicas, pelo endividamento, pelos déficits fiscais, pela redução das taxas de lucro, inflação e demais mazelas da sociedade atual, enquanto a proteção social pública é acusada de promover paternalismo e desestímulo ao trabalho. 
Como destaca Oliveira (1998), os ataques dos neoliberais aos gastos sociais são uma maneira de destruir a relação do fundo público com a estrutura de salário, correção das desigualdades e dos bolsões de pobreza. Ainda, para o autor, os neoliberais não propõem o desmantelamento total das funções do fundo público como antivalor, como suporte à acumulação capitalista, mas visa o repasse da reprodução social dos trabalhadores à esfera privada, sob a máscara do discurso da solidariedade direta, da cooperação, da ampliação da participação 'cidadã', legitimando os novos modelos de intervenção do Estado e repassando para a sociedade civil - completamente destituída de sua acepção materialista e classista - a responsabilidade pelo trato das refrações da questão social.

Essa perspectiva de divisão de responsabilidades no trato da questão social, à medida que reduz a demanda do Estado e restabelece os laços de solidariedade direta, têm seduzido conservadores e "progressistas', e está relacionada ao mix público/privado, com a participação da sociedade civil (incluindo o mercado) na provisão de bens e serviços, restringindo o Estado ao papel de normatizador, fiscalizador e, em alguns casos, financiador. Trata-se de uma nova modalidade de proteção social, agora sob a rubrica de pluralismo de bem-estar, ou bem-estar misto, como alternativa, que mantém os sistemas públicos de intervenção social, mas sob novas bases, mais restritivas - focalizadas e seletivas.

Um dos momentos decisivos na institucionalização de uma nova cultura de fazer política social ocorreu durante a reforma administrativa do Estado brasileiro, elaborada e aprovada pelo governo de Fernando Henrique Cardoso, com o objetivo de adotar uma administração gerencial contrária à burocrática. Entre as medidas para efetivá-la, destacam-se aquelas em que o interesse público não pode ser confundido com o interesse do próprio Estado, como ocorre com a administração burocrática e centralizadora tomada como uma ampliação da esfera pública que se expande para a sociedade civil, cujas ações são de interesse público. Isso tem significado, na verdade, a volta dos serviços sociais para a dimensão privada, lucrativa ou não-mercantil, um ataque aos direitos sociais, garantidos pelos fundos públicos e executados pela burocracia estatal, e um reforço à 'refilantropização' da questão social.

Essas mudanças legais e institucionais públicas vão redesenhar a política social, dando-lhe duas características principais: a) a descentralização e a racionalização dos serviços públicos, que busca reduzir os gastos públicos federais e desresponsabilizar o governo pela execução das políticas sociais repassando-as para as coletividades locais; b) a "publicização", que pretende significar "transformação dos serviços não-exclusivos de Estado em propriedade pública não-estatal e sua declaração como organização social" (BRESSER PEREIRA, 1998, p. 246).

As ações na qual se insere a sociedade civil, mediante suas organizações, nas tarefas de serviços públicos, concebidas pelos reformistas como a via de modernização do desempenho das ações públicas, no intuito de diminuir as demandas do Estado, têm significado um retrocesso. Constituem o retorno para as formas de enfrentamento da questão social, através de ações benemerentes, filantrópicas, ou das formas mais modernas de empresa cidadã, organizações nãogovernamentais, dentre outras. A nova face da proteção social privada não-mercantil assume dimensões ideológicas de espaço público, de organizações progressistas, de representantes do interesse geral e mascara a restrição da ação do Estado na reprodução do conjunto da classe trabalhadora.

\section{Política social de proteção ao idoso: entre o 'público' e o 'privado'}

As leis infraconstitucionais nas diversas áreas de políticas sociais consolidam esse 'novo' modelo de política social que se move entre o 'público' e o 'privado', que legitima a participação da sociedade civil como executora da política. A título de exemplo, a Política Nacional do Idoso (PNI) passou não apenas a regular as diversas iniciativas privadas e públicas de ações de proteção ao idoso, criando princípios e diretrizes para uniformizá-las, mas também a legalizar formalmente e incentivar essas instituições privadas como executoras da política. Instituiu um 'novo' e, ao mesmo tempo, um 'velho' métier de fazer política social no Brasil, marcados por continuísmos históricos nas formas de proteção social, que as lutas por democratização e a Constituição Federal de 1988 não foram capazes de romper e de mudar, sob a retórica da presença da sociedade civil nas decisões, gestão, execução e fiscalização das políticas, expressas nos princípios de descentralização e participação social (BRASIL, 2000).

A PNI firma a descentralização não somente nos aspectos técnico, fiscal ou administrativo, incluindo o que Nogueira (1997) denomina de sua "dimensão política", associada à noção de participação da sociedade tanto nas ações e espaços de controle social, mas também nos aspectos de execução da política, como instância de proteção social, com ou sem os recursos do Estado, reafirmando a definição de participação, como de parceria e de colaboracionismo.

A descentralização que se tenta hoje implementar, como aquela materializada na PNI e no Estatuto do Idoso, busca transferir encargos e, ao mesmo tempo, co-responsabilizar a sociedade civil na gestão de políticas sociais, redefinindo as estratégias de controle social, em colaboracionismo, em novas formas de legitimação das ações e iniciativas do Estado. 
A descentralização como divisão de responsabilidades sociais no trato da problemática social do envelhecimento com a sociedade civil é constante na letra da lei que institui a PNI e os instrumentos para implementá-la. Nessa perspectiva, o primeiro princípio que orienta a lei define: "I - a família, a sociedade e o Estado têm o dever de assegurar ao idoso todos os direitos de cidadania, garantindo sua participação na comunidade, defendendo sua dignidade, bem-estar e o direito à vida"; o segundo também expressa essa responsabilidade social, logo da sociedade para com os idosos: "II - o processo de envelhecimento diz respeito à sociedade em geral, devendo ser objeto de conhecimento e informação para todos" (BRASIL, 2000, p. 6-7).

Assim, torna-se visível a participação da sociedade civil como espaço de efetivação de serviços e proteção social ao idoso, em especial, a modalidade não-mercantil, como a família, que se ancora no processo que Bermúdez (2001 apud MIOTO; LIMA, 2005, p. 6), denomina de "neofamiliarismo", que é definido pela autora como sendo uma "tendência ideológica atual de transformar a unidade familiar em solução para a racionalidade do modelo global, reprivatizando atividades tornadas públicas no passado, e trazendo a unidade doméstica - privada por definição - de volta a sociedade em geral."

O papel dos apoios informais é reconhecido e incentivado cada vez mais no âmbito das políticas públicas. Entretanto, a valorização das redes de solidariedade familiares e comunitárias é pura retórica, à medida que tem significado deixar a família à sua própria sorte, obrigando-a a buscar os serviços no mercado ou perecer na pobreza, se incapaz de pagar pelos serviços. Como destacam Mioto e Lima (2005), parece estar cada vez mais distante a possibilidade da família contar com fonte de recursos para responder às dificuldades sociais, que atinge grande parte da população empobrecida. Situação agravada pelo desemprego e pela precarização do trabalho.

Todavia, a pseudovalorização dessas redes faz parte do discurso neoliberal, do retorno ao âmbito privado da satisfação de necessidades reprodutivas da força de trabalho, de modo a reduzir a demanda do Estado, os custos tributários. E para gerar espaços - até então não-mercantilizados - de reprodução do capital: como na saúde, educação, previdência, fi- cando a ação do Estado restrita a políticas compensatórias da pobreza.

As diretrizes da PNI priorizam o atendimento do idoso na própria família. Se esse procedimento, por um lado, representa mecanismos de desinternação, desasilamento dos idosos, por outro, responsabiliza as famílias e as organizações sociais não-governamentais. O Estado, ficando com sua atuação limitada a casos extremos de pobreza e abandono, deixa de fazer investimentos de porte na política asilar ou em formas alternativas de assistência. As diretrizes confirmam: "III - priorização do atendimento ao idoso através de suas próprias famílias, em detrimento do atendimento asilar, à exceção dos idosos que não possuem condições que garantam sua própria sobrevivência", ou ainda, "VIII - a priorização do atendimento do idoso em órgãos públicos e privados prestadores de serviços, é somente quando desabrigados e sem família" (BRASIL, 2000, p.7-8). Além de o Estado ter restringido sua atuação, a execução da política asilar para os desabrigados e abandonados não é adequada. Posto que nem nesses casos a atuação do Estado é exclusiva. As instituições asilares, por não serem prioritárias, padecem para captação de fundos, passando a ser mantidas pelo município ou por ONG's, precisando apelar para doações privadas e recorrer ao trabalho de voluntários.

Vale ressaltar que os movimentos sociais lutaram pelo desenclausuramento dos idosos, contra o confinamento social, por representarem perda da cidadania, segregação, afastamento dos laços familiares, e por formas alternativas de atendimento aos idosos. Todavia, a redução dos gastos sociais e o retorno da reprodução social para o âmbito privado têm repassado as responsabilidades públicas às famílias, à sociedade civil, cujas propostas de convívio alternativo aos idosos são pioneiras no Brasil.

Em relação às ações governamentais, dentre elas as referentes às áreas de promoção e assistência social, destaca-se o atendimento às necessidades básicas do indivíduo, mediante a participação das famílias, da sociedade, de entidades governamentais e não-governamentais. O princípio básico definidor das ações é sempre a divisão de responsabilidades, das 'parcerias', do retorno à família como espaço de proteção social, e não como sujeito da proteção, que faz parte das estratégias de retomada das redes de 
solidariedade primárias, centralizadas na família, inclusive, nos tratamentos de saúde, com a figura do cuidador e com as ações do chamado terceiro setor. É no espaço da assistência social que mais claramente se apresentam as propostas de parcerias com as organizações não-governamentais, parte do métier ou modus operandi da assistência social no Brasil, aprofundada na era neoliberal.

É nessas ações da assistência social, mas não exclusivamente nesta área, que se materializa a diretriz de "viabilização de formas alternativas de participação, ocupação e convívio do idoso, que proporcionem sua integração às demais gerações" (BRASIL, 2000, p.7). Diz respeito a estimular essas ações, o que significa não executá-las prioritariamente, mas em parceria com a sociedade civil, através de alternativas de atendimento, programas, centros de convivência, casas-lares, oficinas, atendimento domiciliar e outros, complementando, assim, a política de assistência monetária.

A título de exemplo, as propostas de Centros de Convivência para Idosos não apenas afirmam a rede de parceria com instituições públicas e privadas, definidas pelas normas operacionais do Ministério do Desenvolvimento Social e Combate à Fome, mas também determinam que sua gestão busque a autosustentação:

[...] visando à auto-sustentação dos Centros de Convivência. [...] o projeto deverá ser iniciado com uma co-participação entre governo e sociedade. [...] A manutenção das atividades se dará com recursos dos Fundos Nacional, Estadual e Municipal e, quando possível, outras fontes aprovadas pelos respectivos conselhos de Assistência e/ou de Saúde (NORMAS OPERACIONAIS, 2007, p. 34).

Demonstram, portanto, uma redução do papel do governo federal nesses serviços de cuidados institucionais com idosos, não apenas na parte administrativa, também na de pessoal qualificado. Desta forma, as instituições passam a contar com os escassos recursos institucionais dos municípios, cuja contrapartida, aliada ao baixo poder organizativo e estrutural da sociedade civil, pode inviabilizar a efetivação de uma rede qualificada de proteção social ao idoso.

Embora o setor privado (não-mercantil) receba recursos das três instâncias administrativas de governo, as parcerias definem-se também pelo co-financiamento, com outras fontes de doações civis e trabalho voluntário. Essas fontes, apesar de serem avaliadas por muitos analistas como geradoras de mecanismos mais eficientes, porque reduzem custos, têm, na verdade, precarizado os serviços, colocando-os em situação de instabilidade e de incapacidade de atender demandas, sendo, sim, eficientes mecanismos de redução de metas, grupo-alvos, além de conterem ações marcadas pelo localismo e pela trivialidade do atendimento.

Todavia, a descentralização na sua dimensão participativa - portanto, política - não se direciona apenas para a participação da sociedade civil na execução das políticas. Os poderes públicos, porém, têm que conviver com as conquistas dos movimentos pela democratização do Estado e da sociedade que exigem a participação das diversas organizações civis nos espaços de deliberações das diretrizes políticas. Participação nas decisões, no planejamento, no controle e na supervisão de planos, programas e projetos que materializam a política, constituindo a dimensão moderna, as mudanças (numa dialética de continuidades e mudanças) nas formas de enfrentar a questão social.

As diretrizes da PNI reafirmam a participação da sociedade civil, bem como a dos próprios idosos, através de suas organizações representativas, na formulação, implementação e avaliação da política a eles dirigida. Em tese, um avanço que gera espaços de participação e de 'controle social' da gestão pública das políticas, criando mecanismos para que as demandas cheguem aos formuladores dessas políticas, o que, por si só, não é garantia de atendimento das necessidades, considerando-se a demanda reprimida, os parcos recursos federais e a inviabilidade de muitos municípios de co-financiar os programas.

Ainda assim, a institucionalização dos denominados conselhos de direitos ou conselhos gestores órgãos colegiados, constituídos nas instâncias federal, estadual e municipal, por representação paritária da sociedade civil e sociedade política, com funções deliberativas sobre a política social -, no âmbito de cada política específica, ocorre, mas com o avanço do neoliberalismo, em um contexto de reestruturação produtiva e político-ideológica do capital, esses são redirecionados, transformam-se em colaboradores, parceiros. Nessa condição, contraditoriamente constituem um espaço de recomposição das bases de hegemonia e de controle sobre o trabalho, que visa obter a adesão e o consentimento do trabalhador à nova ordem, construindo uma nova cultura de consenso, fundada na solidariedade indiferenciada entre as classes, no cooperativismo, ou solidarismo, no enfrentamento das crises, redefinindo o sentido da participação social.

Como destaca Abreu (1999, p. 64), as medidas persuasivas do capital, para atingir o fim em que o aparato estatal constitui uma das principais mediações, são fundados na retórica de que a "nova relação capital/trabalho, consubstancia-se na superação dos antagonismos entre classes, e no estabelecimento da colaboração entre elas, na qual a parceria e as soluções negociadas constituem a base dessa 'nova' relação." É nessa perspectiva que se reatualiza a intervenção do setor privado na questão social, e que ocorrem os redirecionamentos das práticas de de- 
mocracia direta, no sentido de tornar os sujeitos, que ocupam esses espaços parceiros, colaboradores e legitimadores das decisões governamentais.

Os conselhos são, entretanto, espaços contraditórios. Vinculam-se às iniciativas da classe trabalhadora, referentes à democratização e universalização das políticas públicas. Constituem-se em espaços de expressão política, na luta pela garantia de meios à própria reprodução social, mas também aos objetivos neoliberais de descentralização e partilha do poder. Objetivos esses integrados às estratégias de desregulamentação do papel do Estado na economia e na sociedade, podendo, nesse caso, desenvolverem-se como mecanismos privilegiados de manifestação dos interesses dominantes, e do exercício do controle social pelo capital (ABREU, 1999).

Essa dimensão contraditória, como destaca Silva (2004), significa que o caráter democratizador ou colaboracionista não está a priori, mas sim depende da correlação de forças que se estabelecem na sociedade civil e na sociedade política e entre as classes sociais.

Os limites impostos a essas instâncias pelo Poder Executivo, o seu real poder e autonomia em relação à esfera governamental, e a efetivação das atribuições legais, de decisão e de controle social, dão a dimensão clara do sentido e da direção da noção de participação social que o poder visa instituir.

Em relação à PNI, Lei 8.842 (BRASIL, 2000), esses limites começam com a legislação, considerando-se que o Poder Executivo vetou os artigos (do $11^{\circ}$. ao $18^{\circ}$ ) que criavam e definiam papéis e atribuições do Conselho Nacional dos Direitos do Idoso. Assim, a constituição dessa instância efetivou-se apenas em 2003, realizando-se no primeiro semestre daquele ano a primeira reunião do Conselho Nacional. Em abril de 2004, já existiam 19 Conselhos Estaduais de Direitos do Idoso, sendo que muitos surgiram antes da instância nacional. Em escala municipal vêm crescendo o número de conselhos, embora ainda pouco representativos, se relacionados à quantidade de municípios brasileiros.

No Estatuto do Idoso, Lei 10.741(BRASIL, 2007), o artigo 53 dá nova redação ao artigo 7 da PNI, assinalando que compete aos conselhos, de que trata o artigo 6 dessa lei, a supervisão, o acompanhamento, a fiscalização e a avaliação da Política Nacional do Idoso, no âmbito das respectivas instâncias políticoadministrativas.

Como destaca Faleiros (2006), faltou estabelecer, nessa lei, o caráter deliberativo desses conselhos, na formulação de diretrizes e normas, de modo que elas possam ter força de obrigatoriedade, apesar de que, mesmo com essa função formalizada em lei, as várias instâncias do poder público inviabilizam ou desrespeitam as deliberações tomadas por esses órgãos. O caráter deliberativo do Conselho Nacional foi corrigido pelo Decreto n. 5.109 (BRASIL, 2006), que dispõe sobre a composição, estruturação, competências e funcionamento do Conselho Nacional de Direitos do Idoso.

Todavia, o limite no poder de decisão desses conselhos não se restringe à definição na lei, mas a uma série de mecanismos práticos que inviabilizam que estas instâncias decidam sobre quais necessidades sociais atender e financiar. Como exemplo, a falta de um orçamento único para a execução da PNI constitui um dos obstáculos à efetivação dessa atribuição. Além disso, o orçamento destinado a cobrir determinados programas tem seus recursos depositados nos fundos Nacional de Saúde e de Assistência Social, em áreas específicas. As demais áreas de proteção social ao idoso são desenvolvidas com recursos de cada ministério que envolve essas ações, nem sempre as tendo como prioridade nos gastos sociais.

Mesmo considerando os limites impostos pelo caráter incipiente desses conselhos, que se refletem nos processos de discussão coletiva nos fóruns ${ }^{2}$ de debates com a sociedade civil e política, foi possível delinear suas ações, como a proposta de criação de uma Rede Nacional de Proteção Social e de Direitos da Pessoa Idosa (RENADI), e a realização da Conferência Nacional dos Direitos da Pessoa Idosa com os objetivos específicos de: estimular a criação dos conselhos municipais e fortalecer os já existentes; constituir espaços de apresentação e articulação de proposições para a construção da rede de proteção social e de defesa dos direitos do idoso, esclarecendo o seu caráter, os princípios, a estrutura e a estratégia de sua implementação; identificar os desafios para esta implementação; e deliberar sobre as estratégias de seguimento e de monitoramento das deliberações desse fórum, dentre outros.

A rede de proteção social é definida como uma "organização da atuação pública (do Estado e da sociedade) através da implementação de um conjunto articulado, orgânico e descentralizado de instrumentos, mecanismos, órgãos e ações para realizar todos os direitos fundamentais da pessoa idosa do país" (CONFERÊNCIA..., 2006, p.15). Tal definição exprime bem a noção do público não-estatal, articulada ao Estado na garantia dos direitos, e sua função de responsabilidade direta na proteção social, expressão do cooperativismo frente à questão social.

A defesa dessa "nova institucionalidade pública (estatal e não-estatal) e a promoção de uma nova subjetividade expressa numa nova cultura de direitos da pessoa idosa", conforme o mesmo documento, expressa o caráter da RENADI, e destaca-se como o traço comum entre os discursos progressistas e conservadores, formando um consenso em torno do modo de fazer política social, e de transmutá-la para o âmbito da ajuda solidária.

Embora se concorde que os setores populares, representantes dos interesses das classes dominadas, 
devam ocupar os espaços institucionalizados como estratégia para criar regras pactuadas e universais que possam romper com o que Oliveira (1990) denomina de modelo de regulação truncada, do caso a caso, que favorece apenas os interesses particulares, com o uso dos fundos públicos destinando-se, preferencialmente, para a acumulação do capital, em detrimento dos interesses e necessidades da reprodução da força de trabalho - também se reconhece os limites e os desequilíbrios dessas estratégias.

Nessa perspectiva, os conselhos apresentam possibilidades e limites, principalmente no contexto de reformas neoliberais. Suas deliberações buscam criar tanto instrumentos e estratégias de implementação da legislação existente, como a construção de planos de direitos do idoso em cada esfera administrativa quanto novos órgãos públicos, nos âmbitos do Executivo, Legislativo e Judiciário, de modo a viabilizar uma rede de proteção.

Essas deliberações, contudo, esbarram na vontade do poder público - em especial do Executivo - de democratizar, ou não, as decisões; de respeitar, ou não, as deliberações. Em geral, não há interesse, por parte do poder governamental, em implantar esses órgãos deliberativos e em proporcionar meios para o seu funcionamento. A não ser quando eles são necessários para receber recursos federais para os programas municipais e estaduais, ou quando são usados como instrumentos de ampliação e legitimação de ações políticas de governo.

Os principais obstáculos, principalmente os relacionados ao Conselho Nacional do Idoso, e os congêneres nas outras esferas governamentais, estão relacionados à decisão e à distribuição dos recursos. Isto sem contar com os impedimentos relacionados ao controle e monitoramento das deliberações tomadas. As práticas desse conselho são recentes e ainda não há uma avaliação das decisões tomadas, nem da política nacional. Suas atividade restringemse ao plano das proposições, considerando a inexistência de fóruns de discussões, que só recentemente foram implementados.

Em síntese, os problemas verificados, que limitam as ações dos conselhos de direitos do idoso, são semelhantes aos de outros conselhos, com o agravante da inexistência de mecanismos consolidados de discussão, dada à sua precocidade na realidade brasileira. Dentre esses problemas se destacam: o limitado poder de decisão quanto aos recursos orçamentários constitucionalmente assegurados; o desconhecimento do volume e dos critérios de distribuição dos recursos para o próprio setor e para os demais da área social; a preservação do aparato 'burocrático-cartorial' na legislação e no funcionamento institucional; a efetividade das decisões dos conselhos sendo subordinada à hierarquia burocrática dos órgãos públicos aos quais estão vinculados; e a permeabilidade a ingerências político-particularistas, exercidas através de técnicos e burocratas do Estado (RAICHELES, 1998; SOARES, 2002; CORREIA, 2000).

\section{Conclusão}

A democracia direta expressa nas diretrizes da descentralização e participação social, que apontam para um novo desenho de políticas públicas, principalmente na sua gestão social, tem enfrentado restrições e redirecionamentos postos pelas reformas das políticas sociais, iniciadas na década de 1990, que desnudam os limites do alcance da luta pela democracia, dentro dos aparelhos do Estado capitalista. Sobre isso, Toledo (1994, p. 39 e 196) adverte que "Seria ilusório supor que as classes e frações venham a ocupar posições semelhantes ou de equilíbrio no seu interior [...] Considerando que o processo de socialização da política enfrenta dificuldades de garantir que as classes dominantes aceitem dividir o seu poder", mesmo quando revertem em estratégias de dominação e controle social.

Os limites dessas experiências de co-gestão são expressões dos limites das teses que propõem a controlabilidade do capital pelas mediações políticas, da existência de espaços 'públicos' autônomos e paralelos ao livre desenvolvimento da lógica do capital, como se fosse possível autonomizar as experiências institucionais das leis gerais da auto-reprodução do capital.

Considerando-se conforme Mészáros (2002, p. 368), que "o objetivo de tomada de decisão, e a correspondente autoridade não-escrita (ou não formalizada) do capital enquanto um modo de controle real precede a autoridade estritamente delegada [...] dos próprios capitalistas", o que se dirá da autoridade estritamente delegada (formalmente) dos setores populares e da capacidade de controle dessas instâncias, perante esse controle estrutural do capital, inerente à estruturação da ordem social. O que não significa o fim das lutas pela ocupação desses espaços, que são contraditórios e expressão de diferentes noções de participação e interesses, mas a clareza dos seus limites na ordem capitalista.

\section{Referências}

ABREU, M. M. A relação entre Estado e a sociedade civil - a questão dos Conselhos de Direitos e a participação do Serviço Social. Serviço Social \& Movimento Social, São Luís: EDUFMA, v.1, n.1, p. 61-76, 1999.

.; LOPES, J. B.; CARDOSO, F. G. A questão da solidariedade e a organização/reorganização da cultura: 
dimensão ideológica e atualização de estratégias. In: VIII ENPESS. Anais do VIII ENPESS. Juiz de Fora: ABEPSS, 2002. 1 CD Rom.

BRASIL. Constituição da República Federativa do Brasil. Promulgada em 5 out. 1988. São Paulo: Atlas, 1999.

. Lei 8.842, de 04 de janeiro de 1994. Dispõe sobre a Política Nacional do Idoso, e dá outras providências. Brasília-DF: MPA/SAS, 2000.

. Decreto n. 5.109, de 17 de junho de 2004. Dispõe sobre a composição, estruturação, competências e funcionamento do Conselho Nacional dos Direitos do Idoso - CNDI, e dá outras providências. Disponível em: <www.planalto.gov.br/ccivil/ Ato2004-2006/2004/Decreto/ D5109.htm>. Acesso em: dez 2006.

. Lei 10.741, de 01 de outubro de 2003. Dispõe sobre o Estatuto do idoso e dá outras providências Brasília-DF. Disponível em: <www6.senado.gov.br/legislacao/ ListaPublicacoes.action?id=237486 $>$. Acesso em: fev. 2007. BRESSER PEREIRA, L. C. Reforma do Estado para a cidadania: a reforma gerencial brasileira na perspectiva internacional. São Paulo: Editora 34, 1998.

\section{CONFERÊNCIANACIONALDOSDIREITOSDA PESSOA}

IDOSA. Brasília, 2006. Disponível em: <www.mj.gov.br/ $\mathrm{sedh} / \mathrm{ct} / \mathrm{cndi} / \mathrm{i}$ conferencia idoso.htm $>$. Acesso em: nov. 2006.

CORREIA, M. V. C. Que controle social? Os conselhos de saúde como instrumento. Rio de janeiro: FIOCRUZ, 2000. FALEIROS, V. de P. Os conselhos do idoso: controle social e democracia participativa. In: .; LOUREIRO, A. M. L. (Org). Desafios do envelhecimento: vez, sentido e voz. Brasília: Universa, 2006, p. 88-103.

GUERRA. Y. A racionalidade das formas de enfrentamento da questão social: o público e o privado no Brasil (do) real. In: JORNADA INTERNACIONAL DE POLÍTICAS PÚBLICAS, 2, 2005, São Luís. Anais... Maranhão: UFMA, 2005. 1 CD-ROM.

MÉSZÁROS, I. Para além do capital: rumo a uma teoria da transição. São Paulo: Editora da UNICAMP/Boitempo Editorial, 2002.

MIOTO, R. C. T; LIMA, T. C. S. de. Quem cobre as insuficiências das políticas públicas. In: JORNADA INTERNACIONAL EM POLÍTICAS PÚBLICAS, 2, 2005, São Luís. Anais... Maranhão, 2005. 1 CD-ROM.

NOGUEIRA, M. A. Adimensão política da descentralização participativa. São Paulo em Perspectiva, São Paulo: SEADE, v. 11, n. 3, p. 8-19, jul-set 1997.
NORMAS OPERACIONAIS. Ministério do Desenvolvimento Social e Combate à Fome, Brasília, 2006. Disponível em: 〈www.mds.gov.br〉. Acesso em: 12 mar. 2007.

OLIVEIRA, F. de. O surgimento do antivalor: capital força de trabalho e fundo público. Novos estudos CEBRAP, São Paulo, n. 22, p. 8-28, out. 1988.

. Os protagonistas de um drama: Estado e sociedade no Brasil. In: LARANJEIRA, S. (Org.) Classes sociais e movimentos sociais na América Latina. São Paulo: Hucitec, 1990, p. 43-66.

PAULO NETTO, J. FHC e a política social: um desastre para as massas trabalhadoras. In: LESBAUPIN, I. (Org.). $O$ desmonte da nação: balanço do governo FHC. Petrópolis: Vozes, 1999. p. 75-89.

RAICHELES, R. Esfera pública e conselhos de assistência social: caminhos da construção democrática. São Paulo: Cortez, 1998.

SILVA, A. X. da. Conselhos de políticas públicas - espaços de ampliação da democracia? In: IX ENPESS, Porto Alegre, 2004. Anais... Porto Alegre: ABEPSS/PUCRS, 2004. 1 CDROM.

SOARES, L. T. R. Os custos sociais do ajuste neoliberal na América Latina. São Paulo: Cortez, 2002 (Coleção questões da nossa época, v.78).

TOLEDO, C. N. de. As esquerdas e a redescoberta da democracia. In: DAGNINO, E. (Org.) Anos 90 - política e sociedade no Brasil. São Paulo: Brasiliense, 1994, p. 127136.

VIANNA, M. L. T. W. Que reforma? O sistema brasileiro de proteção social entre a previdência e a seguridade. Ser Social, Brasília: UNB, n. 11, p. 75-104, 2002.

\section{Notas}

1 Conforme Abreu et al (2002, p.2) "a solidariedade social é, pois, o contraponto da solidariedade de classe e afirma-se concretamente como uma modalidade de ideologização e mascaramento da distribuição desigual e da suposta superação dos antagonismos de classe". Contraditoriamente, também expressou o reconhecimento público e estrutural dos problemas sociais que afetavam a classe trabalhadora, e cuja reprodução social passou a ser garantida pelos fundos públicos. A solidariedade local e voluntária é um retrocesso no curso de reconhecimento da questão social e de enfrentamento público, embora visassem ao controle da classe trabalhadora e a quebrar a solidariedade de classe. Esta nova estratégia trata de reatualizar a 
solidariedade entre classes antagônicas e responsabilizar os sujeitos e indivíduos pelo seu próprio bem-estare problemas sociais, mas mantendo e ampliando a reprodução do capital com os fundos públicos.

2 Esses fóruns de debates culminaram com as primeiras Conferências Estaduais dos Direitos da Pessoa Idosa, realizadas em 2006, como preparação para a Conferência Nacional dos Direitos da Pessoa Idosa, realizada em Brasília, em maio de 2006, que teve como objetivo geral definir estratégias para a implantação da Rede Naconal de Proteção Social e de Direitos da Pessoa Idosa (RENADI).

\section{Solange Maria Teixeira}

Mestre em Serviço Social pela Pontifícia Universidade Católica de São Paulo (PUCSP)

Doutora em Políticas Públicas pela Universidade

Federal do Maranhão (UFMA)

Professora adjunta da Universidade Federal do

Piauí (UFPI)

UFPI - Centro de Ciências Humanas e Letras, Departamento de Serviço Social.

Campus da Ininga, $\mathrm{S} / \mathrm{N}$

Ininga

Teresina - Piauí

CEP: 64048-110 